\title{
The solution of the plane problem of the theory of elasticity by the boundary elements method
}

\author{
Mykola Surianinov ${ }^{1 *}$, Yurii Krutii ${ }^{1}$, Anatolii $\operatorname{Kovrov}^{1}$ and Vladimir Osadchiy ${ }^{1}$ \\ ${ }^{1}$ Odessa State Academy of Civil Engineering and Architecture, Didrikson str., 4, Odessa, 65029, \\ Ukraine
}

\begin{abstract}
An approach to solving the biharmonic equation of the plane problem of the theory of elasticity by the numerical-analytical method of boundary elements is developed. The reduction of the two-dimensional problem to the one-dimensional one was carried out by the KantorovichVlasov method. Systems of fundamental orthonormal functions and the Green function are constructed without any restrictions on the nature of the boundary conditions. A numerical example of solving a plane problem by the boundary element method for a rectangular plate is considered. The results are compared with the data of finite element analysis in the ANSYS program and those obtained by A.V. Aleksandrov.
\end{abstract}

\section{Introduction}

As you know, there are two types of plane problems that describe two different types of stress-strain state - plane stress state (PSS) and plane deformed state (PDS), which are described by the same mathematical apparatus and therefore are combined into one problem - a plane problem of elasticity theory [1].

PSS or PDS occurs in many structures. So, thin plates, beam-walls, shells work in conditions of a plane stress state, and dams, strip foundations, road surfaces undergo plane deformation. Such a wide coverage of objects (and not all are listed), indicates that the development of new methods for solving a flat problem continues to be an urgent problem.

\subsection{Recent research and publication analysis}

The main methods for solving a plane problem are well known and described in numerous classical literature on the theory of elasticity [2-4]. However, a solution in an analytical form is possible only in some special cases of loading bodies of simple geometric shape and the conditions for their fastening. Therefore, approximate methods are used to implement applied engineering problems.

Research in this area is actively ongoing. From the works of recent years, we note the article [6], which presents the procedure and results of the numerical solution of plane problems of the linear theory of elasticity for complex construction geometry by the direct method of boundary elements. A.G. Ovsky [7] gives algorithms for automating analytical

*Corresponding author: $\underline{\text { sng@ ogasa.org.ua }}$ 
methods by which the preprocessor preliminarily derives the symbolic differential solution of the general problem of the static theory of elasticity for multilayer bodies. The algorithms used to construct the models are general in nature and can be applied to any of the systems of computer mathematics. In the article [8], the formulation and implementation scheme of a new method for solving plane problems of the theory of elasticity based on the diagonalization of a system of equilibrium equations is presented; analytical solutions of three plane problems in voltages for loading the strip with a complex load are obtained.

In [9], an analytical solution was constructed for the plane problem of the theory of elasticity in stresses for a nonuniform bandwidth. To derive resolving equations, direct integration of the original equations is performed. In the space of Fourier transforms, the resolving equations are reduced to the Volterra integral equation of the second kind, which is solved by the method of successive approximations. The method of a general complex variable function for solving a plane problem in the theory of elasticity was proposed in [10]. The paper [11] describes a numerical solution of a plane problem. Here, the discretization algorithms by the mixed finite element method are described. The discrete circuit allows the use of the Brezzy - Douglas - Marini element (BDM1) for the stress tensor and piecewise constant elements for displacement. A comparison is made with the results of previously published works and with those obtained in ABAQUS.

\subsection{Study purpose and objective}

The aim of this work is to solve the equation of the plane problem of the theory of elasticity based on the numerical-analytical method of boundary elements [12, 13] (NA BEM) without any restrictions on the nature of the boundary conditions. To achieve this goal, it is necessary to determine the complete system of fundamental solutions of the biharmonic equation of the problem, to construct the Green's function, to perform a numerical implementation of the FEM algorithm and to verify the results obtained.

\subsection{Main part of the study}

To solve a flat problem in stresses, the stress function $\varphi$ is used $-D$. Erie function, defined in the form [14].

$$
\sigma_{x}=\frac{\partial^{2} \varphi}{\partial y^{2}}, \sigma_{y}=\frac{\partial^{2} \varphi}{\partial x^{2}}, \tau_{x y}=-\frac{\partial^{2} \varphi}{\partial x \partial y} .
$$

When using the stress function, the basic equation of the plane problem takes the form:

$$
\frac{\partial^{4} \varphi}{\partial x^{4}}+2 \frac{\partial^{4} \varphi}{\partial x^{2} \partial y^{2}}+\frac{\partial^{4} \varphi}{\partial y^{4}}=0
$$

Using the Kantorovich-Vlasov method, we reduce the two-dimensional problem to the one-dimensional one. We define the stress function in the form of an infinite series.

$$
\varphi=\sum_{m=1}^{\infty} Y_{m}(y) X_{m}(x)
$$

We will not specify the form of the function $X$ for now, but in expansion (3) we keep only the first member of the series: 


$$
\varphi=Y(y) X(x) .
$$

We substitute (4) into the biharmonic equation (2):

$$
X^{I V} Y+2 X^{I I} Y^{I I}+X Y^{I V}=0 .
$$

Multiply both sides of equation (5) by $X$ and integrate on the segment $\left[0 ; l_{1}\right]$ :

$$
Y^{I I} X^{2}+2 Y^{I I} X^{I I} X+Y X^{I V} X=0
$$

and after integration:

$$
Y^{I V} \int_{0}^{l_{1}} X^{2} d x+2 Y^{I I} \int_{0}^{l_{1}} X^{I I} X d x+Y \int_{0}^{l_{1}} X^{I V} X d x=0 .
$$

We introduce the notation:

$$
A=\int_{0}^{l_{1}} X^{2} d x ; B=\int_{0}^{l_{1}} X^{I I} X d x ; C=\int_{0}^{l_{1}} X^{I V} X d x
$$

Then

$$
Y^{I V} A+2 Y^{I I} B+Y C=0 .
$$

Note $B / A=-r^{2} ; C / A=s^{4}$, we will get

$$
Y^{I V}-2 r^{2} Y^{I I}+s^{4} Y=0
$$

Now we express the stresses and displacements through the functions $Y$ and $X$.

The normal and tangential stresses in the plane problem of the theory of elasticity are defined as:

$$
\sigma_{x}=\frac{\partial^{2} \varphi}{\partial y^{2}}=Y^{I I} X, \sigma_{y}=\frac{\partial^{2} \varphi}{\partial x^{2}}=Y X^{I I}, \tau_{x y}=-\frac{\partial^{2} \varphi}{\partial x \partial y}=-Y^{I} X^{I}
$$

Multiply both sides of (7) by $X$ and integrate from 0 to $l_{l}$ :

$$
\begin{aligned}
& \int_{0}^{l_{1}} \sigma_{x} X d x=Y^{I I} \int_{0}^{l_{1}} X^{2} d x, \\
& \int_{0}^{l_{1}} \sigma_{y} X d x=Y \int_{0}^{l_{1}} X^{I I} X d x, \\
& \int_{0}^{l_{1}} \tau_{x y} X d x=-Y^{I} \int_{0}^{l_{1}} X^{I} X d x .
\end{aligned}
$$

We divide each of the equations (8) by $A$ :

$$
\begin{gathered}
\sigma_{x}^{*}=Y^{I I} ; \\
\sigma_{y}^{*}=-r^{2} Y ;
\end{gathered}
$$




$$
\tau_{x y}^{*}=-t^{2} Y^{I}
$$

where $\sigma_{x}^{*}, \sigma_{y}^{*}, \tau_{x y}^{*}$ - generalized stresses, defined by expressions

$$
\begin{gathered}
\sigma_{x}^{*}(y)=\int_{0}^{l_{1}} \sigma_{x}(x, y) X d x / A ; \\
\sigma_{y}^{*}(y)=\int_{0}^{l_{1}} \sigma_{y}(x, y) X d x / A ; \\
\tau_{x y}^{*}(y)=\int_{0}^{l_{1}} \tau_{x y}(x, y) X d x / A ; \\
t^{2}=\frac{C^{*}}{A} ; C^{*}=\int_{0}^{l_{1}} X^{I} X d x .
\end{gathered}
$$

Find the generalized displacements $u$ and $v$ corresponding to the generalized stresses (9):

$$
\begin{aligned}
& \frac{\partial u}{\partial x}=\frac{1}{E}\left(\sigma_{x}-\mu \sigma_{y}\right) \\
& \frac{\partial v}{\partial y}=\frac{1}{E}\left(\sigma_{y}-\mu \sigma_{x}\right) ; \\
& \frac{\partial u}{\partial y}+\frac{\partial v}{\partial x}=\frac{2(1+\mu)}{E} \tau_{x y} .
\end{aligned}
$$

We set for $u$ and $v$ the relations:

$$
\begin{aligned}
& u(x, y)=u^{*}(y) X^{I}(x) ; \\
& v(x, y)=v^{*}(y) X(x) .
\end{aligned}
$$

After substituting in (10) we obtain:

$$
\begin{gathered}
E u^{*} X^{\prime \prime}=Y^{\prime \prime} X-\mu Y X^{\prime \prime} ; \\
E\left(v^{*}\right)^{\prime} X=Y X^{\prime \prime}-\mu Y^{\prime \prime} X ; \\
E\left[\left(u^{*}\right)^{\prime} X^{\prime}+v^{*} X^{\prime}\right\rfloor=-2(1+\mu) Y^{\prime} X^{\prime} .
\end{gathered}
$$

Multiplying, as before, each of the relations (11) by $X$ and integrating in the range from 0 to $l_{l}$, after transformations we obtain generalized displacements in the form

$$
\begin{gathered}
E r^{2} u^{*}=-Y^{\prime \prime}-\mu r^{2} Y . \\
E r^{2} v^{*}=-Y^{\prime \prime}-(2+\mu) r^{2} Y^{\prime} .
\end{gathered}
$$

We proceed to the definition of generalized forces. Normal and shear forces are determined by the expressions: 


$$
\begin{aligned}
& N=h \frac{\partial^{2} \varphi}{\partial x^{2}}=h Y X^{\prime \prime} ; \\
& S=-h \frac{\partial^{2} \varphi}{\partial x \partial y}=-h Y^{\prime} X^{\prime} .
\end{aligned}
$$

Assuming $h=1$, we multiply (14) by $X$ and calculate integrals in the range from 0 to $l_{l}$ :

$$
\begin{aligned}
& N=h \frac{\partial^{2} \varphi}{\partial x^{2}}=h Y X^{\prime \prime} \\
& S=-h \frac{\partial^{2} \varphi}{\partial x \partial y}=-h Y^{\prime} X^{\prime} .
\end{aligned}
$$

We divide each of the equalities by $A$, then the generalized forces take the form

$$
\begin{aligned}
& N^{*}=-r^{2} Y ; \\
& S^{*}=-t^{2} Y^{\prime},
\end{aligned}
$$

where

$$
\begin{aligned}
& N^{*}=\int_{0}^{l_{1}} N X d x / A ; \\
& S^{*}=\int_{0}^{l_{1}} S X d x / A .
\end{aligned}
$$

Note that the function $X(x)$ must satisfy first of all the static and, if possible, kinematic boundary conditions at the longitudinal edges of the plate [12], while when bending the plate, the requirements for the function $X(x)$ will be directly opposite.

Consequently, different boundary conditions of the bend and the plane problem lead to the same expressions for the fundamental functions and the form of the function $X(x)$.

State vector of a plane problem:

$$
\left.\vec{P}=\left\|\begin{array}{l}
N^{*} \\
S^{*} \\
E V^{*} \\
E U^{*}
\end{array}\right\|=\| \begin{array}{l}
-r^{2} Y \\
-t^{2} Y^{\prime} \\
\frac{1}{r^{2}}\left[Y^{\prime \prime \prime}-(2+\mu) r^{2} Y^{\prime}\right] \\
\frac{1}{r^{2}}\left(-Y^{\prime \prime}-\mu r^{2} Y\right)
\end{array}\right] .
$$

We define the fundamental orthonormal functions of the problem under different fixing conditions. Following V.Z. Vlasov [15], by orthonormalized fundamental functions we mean functions that form a unit matrix at a point $x=0$.

The solution of equation (6) depends [16] on the roots of the characteristic equation

$$
k^{4}-2 r^{2} k^{2}+s^{4}=0
$$

where

$$
k_{1-4}= \pm \sqrt{r^{2} \pm \sqrt{r^{4}-s^{4}}}
$$


It follows from (17) that the form of the fundamental functions is determined by the relation between $r$ and $s$, which, in turn, depends on the boundary conditions at the longitudinal edges.

Using the Kolosov - Muskhelishvili analogy [17], we can establish a correspondence between the boundary conditions of the theory of plate bending and the boundary conditions of the plane problem of the theory of elasticity.

Consider the basic conditions for fixing the edges in the direction of the $y$-axis.

Option 1: $s>r$. The case of free edges of the longitudinal edges.

$$
k_{1-4}= \pm \alpha \pm \beta_{i}
$$

where

$$
\alpha=\sqrt{\frac{s^{2}+r^{2}}{2}} ; \beta=\sqrt{\frac{s^{2}-r^{2}}{2}} .
$$

Function $Y$ has the form

$$
Y=C_{1} \Phi_{1}+C_{2} \Phi_{2}+C_{3} \Phi_{3}+C_{4} \Phi_{4}
$$

where $\Phi_{1}, \Phi_{2}, \Phi_{3}, \Phi_{4}$ - hyperbolic trigonometric functions:

$$
\Phi_{1}=\operatorname{ch} \alpha y \sin \beta y ; \Phi_{2}=\operatorname{ch} \alpha y \cos \beta y ; \Phi_{3}=\operatorname{sh} \alpha y \cos \beta y ; \Phi_{4}=\operatorname{sh} \alpha y \sin \beta y .
$$

Constants $C_{1}, C_{2}, C_{3}, C_{4}$ can be determined from ratio

$$
\bar{\Phi}_{0} \bar{C}_{i}=\bar{P}_{0}, i=1,2,3,4 .
$$

Column-vector $\vec{P}_{0}$ contains generalized kinematic and static factors.

We proceed to the determination of the fundamental functions of the problem.

$$
\begin{aligned}
& A_{11}=\Phi_{2}-\frac{r^{2}(1+\mu)}{2 \alpha \beta} \Phi_{4} ; \quad A_{12}=\frac{r^{2}\left(s^{2}+\mu r^{2}\right)}{2 s^{2} t^{2} \beta} \Phi_{1}+\frac{r^{2}\left(s^{2}-\mu r^{2}\right)}{2 s^{2} t^{2} \alpha} \Phi_{3} \\
& A_{13}=\frac{E r^{4}}{2 s^{2} \alpha} \Phi_{3}-\frac{E r^{4}}{2 s^{2} \beta} \Phi_{1}=\frac{E r^{4}}{2 \alpha \beta s^{2}}\left[-\alpha \Phi_{1}+\beta \Phi_{3}\right] ; \quad A_{14}=\frac{E r^{4}}{2 \alpha \beta} \Phi_{4} .
\end{aligned}
$$

Option 2: $s=r$. Case of simple support of longitudinal edges.

$$
k_{1-4}= \pm \sqrt{r^{2}} .
$$

Function $Y(y)$ again taken in the form of (18), but here

$$
\Phi_{1}=y c h r y ; \Phi_{2}=\text { chry } ; \Phi_{3}=\text { shry } ; \Phi_{4}=y s h r y .
$$

Option 3: $s<r$. Case of longitudinal edges fixing.

The characteristic equation (16) has two real and different roots: 


$$
\lambda_{1}=\sqrt{r^{2}+\sqrt{r^{4}-s^{4}}} ; \lambda_{2}=\sqrt{r^{2}-\sqrt{r^{4}-s^{4}}} .
$$

We take function $Y(y)$ in the form (18), but here

$$
\Phi_{1}=\operatorname{sh} \lambda_{2} y ; \Phi_{2}=\operatorname{ch} \lambda_{1} y ; \Phi_{3}=\operatorname{sh} \lambda_{1} y ; \Phi_{4}=\operatorname{ch} \lambda_{2} y .
$$

Option 4: $s=0$.

The roots of equation (16) will be real and multiple:

$$
k_{1,2}=0 ; k_{3,4}= \pm r_{1} \text {, }
$$

where $r_{1}^{2}=-\frac{2 \mathrm{~B}}{\mathrm{~A}}$.

The expression for the function $Y(y)$ remains in the form (18), but here

$$
\Phi_{1}=\operatorname{sh} r_{1} y ; \Phi_{2}=1 ; \Phi_{3}=y ; \Phi_{4}=c h r_{1} y .
$$

We proceed to the construction of the Green function.

The most convenient form for the particular solution of a linear inhomogeneous differential equation with constant coefficients is the expression

$$
y_{*}(y)=\int_{0}^{y} G(y, \xi) q(\xi) d \xi
$$

where $G(y, \xi)$ - Green's function, whose construction algorithm is independent of the boundary conditions of the problem [18].

Consider the implementation of this algorithm for the case of free edges of the longitudinal edges of the plate. In our case $a_{0}$ in main differential equation is equal to one, that's why for integration constants $C_{1}, C_{2}, C_{3}, C_{4}$ we came to the system of linear algebraic equations

$$
\left\{\begin{array}{l}
y_{1} C_{1}+y_{2} C_{2}+y_{3} C_{3}+y_{4} C_{4}=0 \\
y_{1}^{\prime} C_{1}+y_{2}^{\prime} C_{2}+y_{3}^{\prime} C_{3}+y_{4}^{\prime} C_{4}=0 ; \\
y_{1}^{\prime \prime} C_{1}+y_{2}^{\prime \prime} C_{2}+y_{3}^{\prime \prime} C_{3}+y_{4}^{\prime \prime} C_{4}=0 \\
y_{1}^{\prime \prime} C_{1}+y_{2}^{\prime \prime \prime} C_{2}+y_{3}^{\prime \prime \prime} C_{3}+y_{4}^{\prime \prime \prime} C_{4}=1,
\end{array}\right.
$$

where

$$
y_{1}=\operatorname{ch} \alpha \xi \sin \beta \xi ; \quad y_{2}=\operatorname{ch} \alpha \xi \cos \beta \xi ; \quad y_{3}=\operatorname{sh} \alpha \xi \cos \beta \xi ; \quad y_{4}=s h \alpha \xi \sin \beta \xi .
$$

Solving system (22) by the Gauss method, we obtain 


$$
\left\{\begin{array}{l}
C_{1}=\frac{\alpha \operatorname{ch} \alpha \xi \cos \beta \xi+\beta \operatorname{sh} \alpha \xi \sin \beta \xi}{2 \alpha \beta\left(\alpha^{2}+\beta^{2}\right)} \\
C_{2}=\frac{-\alpha \operatorname{ch} \alpha \xi \sin \beta \xi+\beta \operatorname{sh} \alpha \xi \cos \beta \xi}{2 \alpha \beta\left(\alpha^{2}+\beta^{2}\right)} \\
C_{3}=\frac{\alpha \operatorname{sh} \alpha \xi \sin \beta \xi-\beta \operatorname{ch} \alpha \xi \cos \beta \xi}{2 \alpha \beta\left(\alpha^{2}+\beta^{2}\right)} \\
C_{4}=\frac{-\alpha \operatorname{sh} \alpha \xi \cos \beta \xi-\beta \operatorname{ch} \alpha \xi \sin \beta \xi}{2 \alpha \beta\left(\alpha^{2}+\beta^{2}\right)}
\end{array}\right.
$$

Taking into account (21) and (23), for the Green's function we obtain after simple transformations

$$
G(y, \xi)=\frac{1}{2 \alpha \beta\left(\alpha^{2}+\beta^{2}\right)}[\alpha \operatorname{ch} \alpha(y-\xi) \sin \beta(y-\xi)-\beta \operatorname{sh} \alpha(y-\xi) \cos \beta(y-\xi)]
$$

It is easy to verify that function (24) has all the properties characteristic of the Green function [18].

A comparison of (24) with the expressions of fundamental functions obtained earlier shows that

$$
G(y, \xi)=-A_{13}(y-\xi)
$$

From the procedure for compiling the biharmonic equation, the expression for external loads reduced to the median plane of the plate follows:

$$
q(x, y)=\int \frac{\partial^{2} q_{x}^{0}}{\partial y^{2}} d x+\int \frac{\partial^{2} q_{y}^{0}}{\partial x^{2}} d y-\mu \frac{\partial q_{x}^{0}}{\partial x}-\mu \frac{\partial q_{y}^{0}}{\partial y},
$$

where $q_{x}^{0}$ and $q_{y}^{0}$ they are, generally speaking, the sums of volumetric (applied inside the contour of the plate) and surface (applied along the contour) loads in the directions of the $x$ and $y$ axes, respectively.

In most cases, there are no volumetric loads, therefore in the future we will mean by $q_{x}^{0}$ and $q_{y}^{0}$ only contour loads. In general case of loading $q_{x}^{0}$ and $q_{y}^{0}$ - this is a set of eight load groups - two on each side of the circuit (normal and tangential).

Expressions of all acting loads can be written using the Heaviside H-function and the Dirac $\delta$-function, as shown in [12].

As an example, consider a rigidly clamped square plate with free longitudinal (along the axis oy ) edges (Fig. 1). Material — steel (modulus of elasticity $E=2 \cdot 10^{5} M \Pi a$, Poisson's ratio $\mu=0,3$ ), plate thickness $-0,01 \mathrm{~m}$. Let us consider the formation of the equation of the boundary value problem of the NA BEM. The solution of the biharmonic equation (2) is reduced to the solution of an equation of the form.

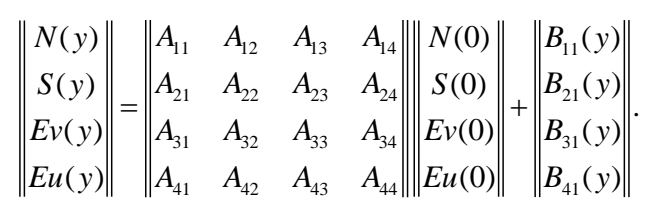


To construct the Eri stress function $\varphi(x, y)$, it is necessary to take into account the boundary conditions for the plate in accordance with Fig. 1. In the direction of the axis $o x$ (free edges), the boundary conditions are taken into account by the function $X(x)$, and in the direction of the axis oy (one edge is rigidly clamped, the other is free), the boundary conditions will be satisfied by a function $N(y)=-r^{2} Y(y)$, that is defined as follows:

$$
N(y)=A_{11}(y) N(0)+A_{12}(y) S(0)+A_{13}(y) E v(0)+A_{14}(y) E u(0)+B_{11}(y) .
$$

For the conditions under consideration, we have

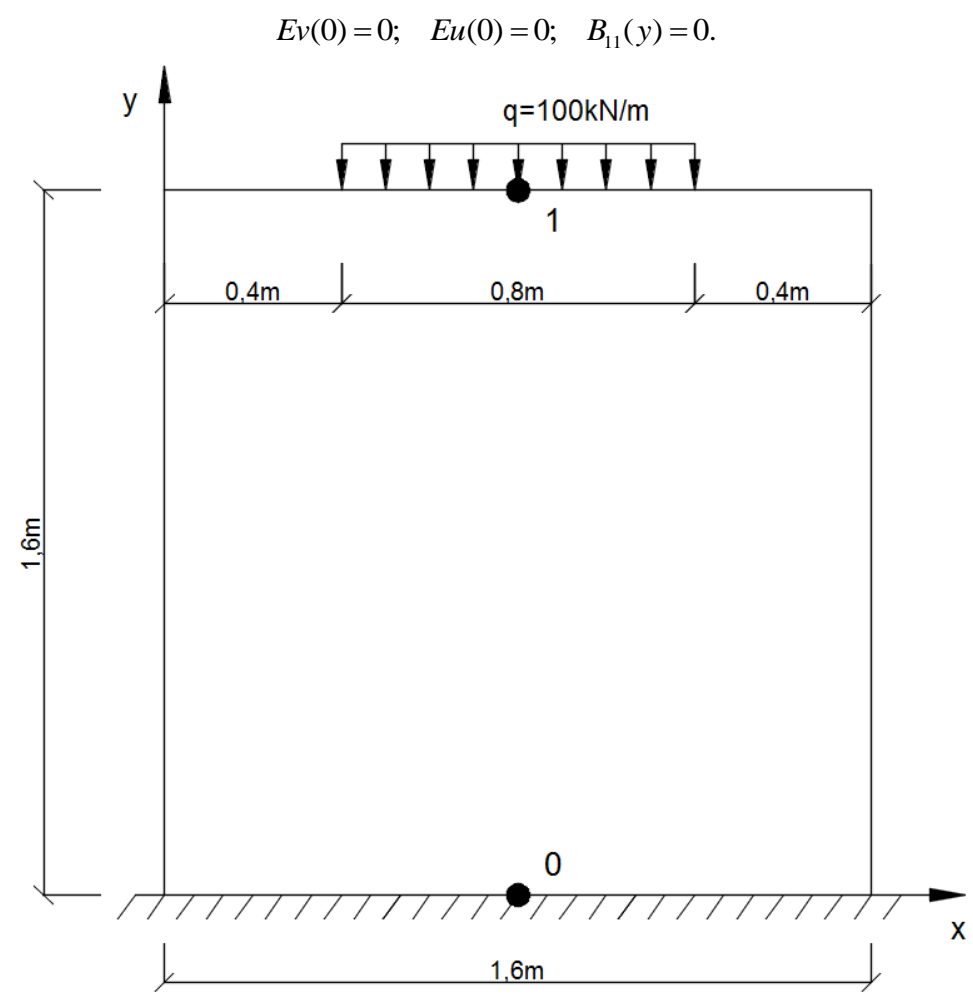

Fig. 1. Calculation example.

Other initial parameters can be determined from the equation of the boundary value problem. The latter is formed taking into account the initial and final boundary parameters:

$$
\left\|\begin{array}{cccc}
A_{11} & A_{12} & 0 & 0 \\
A_{21} & A_{22} & 0 & 0 \\
A_{31} & A_{32} & -1 & 0 \\
A_{41} & A_{42} & 0 & -1
\end{array}\right\|\left\|\begin{array}{c}
N(0) \\
S(0) \\
E v(0) ; E v(l) \\
E u(0) ; E u(l)
\end{array}\right\|-\left\|\begin{array}{c}
N(l) \\
S(l) \\
E v(l) \\
E u(l)
\end{array}\right\|=-\left\|\begin{array}{c}
B_{11}(l) \\
B_{21}(l) \\
B_{31}(l) \\
B_{41}(l)
\end{array}\right\| .
$$

In these transformations, columns 3 and 4 must be zeroed out (this takes into account zero initial parameters), and compensating elements should be put in place of the released matrix $\bar{A}(l)$ elements. The solution of equation (26) allows us to determine nonzero initial parameters $N(0)$ and $S(0)$. Then the stress function takes the form 


$$
\varphi(x, y)=-\frac{1}{r^{2}}\left[A_{11}(y) N(0)+A_{12}(y) S(0)\right] X(x) .
$$

Next, you can determine all the other parameters of the stress-strain state of the plate. The calculation program in Scilab [19], compiled in accordance with the developed algorithm, is implemented for the case of free longitudinal edges; other boundary conditions on the longitudinal edges of the plate lead to the replacement of the fundamental functions and the load vector, and the change in the conditions for fixing the transverse edges is taken into account by the corresponding boundary-value problem of determining the function. In this case, the form of the main BEM equation and the calculation algorithm remain unchanged.

Calculated values of normal stresses $\sigma(x, y)$ and displacements $v(x, y)$ are given in the Tables 1 and 2.

Let us consider the solution to this problem in the ANSYS program. We accept the same initial data as in the calculation by the boundary element method.

To approximate the model, a 4-node finite element was used. In the initial calculation, the surface of the plate was divided into 400 finite elements. In the future, for the convenience of comparing the calculation results in ANSYS with the calculations using the algorithm of the NA BEM and with the solution of A.V. Aleksandrov [14], a larger finite element mesh (100 elements) was adopted. Comparison of these two calculation options in ANSYS shows almost complete identity of the results and, therefore, the enlargement of the grid can be considered correct.

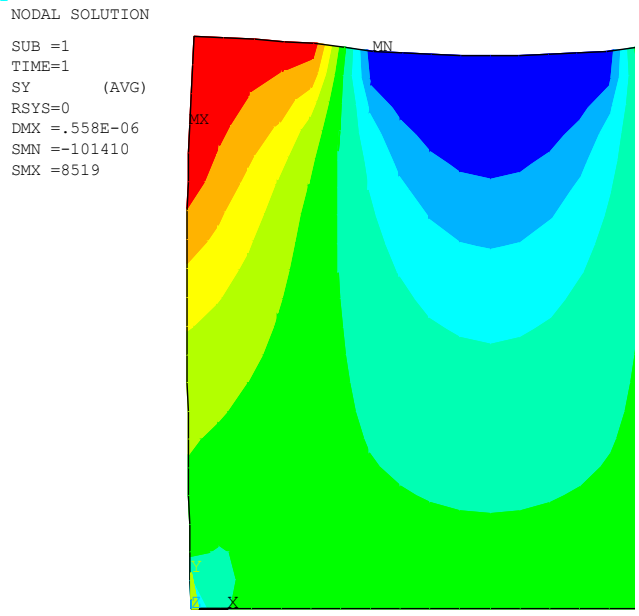

$-101410$

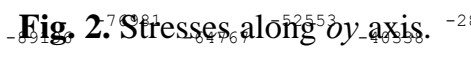

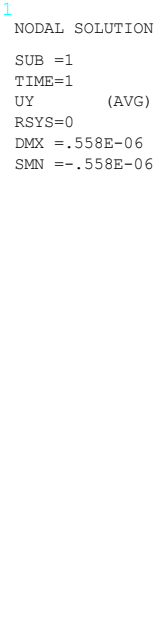

-.558в-06 Fig. 3.4 Displacementeakong oy axis ${ }^{06}$

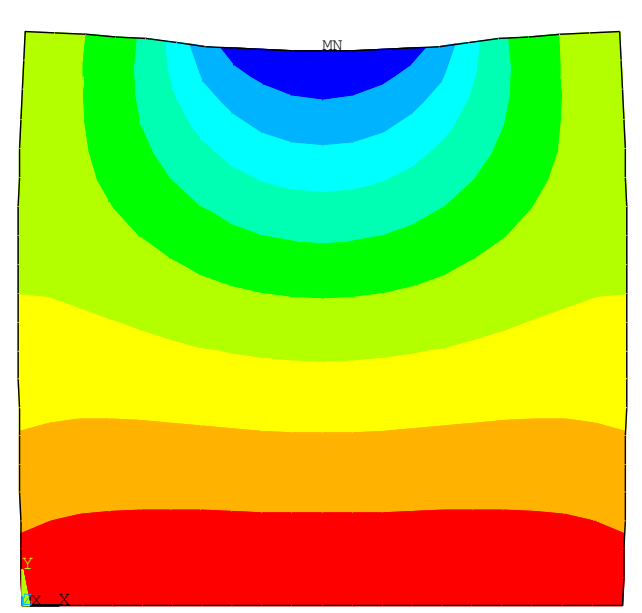

In [14], a method for solving a planar problem is considered, which is based on the reduction of two-dimensional (and three-dimensional) problems to one-dimensional using the Kantorovich - Vlasov method.

The limitation of the algorithm for solving the flat problem developed here (that is, in [14]) is that the solution is obtained only for one version of the boundary conditions and is not universal. The numerical values of stresses and displacements, especially in the regions of the plate located near the longitudinal edges, also raise certain doubts about the accuracy of the results. 
The loading diagram of a square plate, boundary conditions, and stress and displacement diagrams obtained in [14] by this method are shown in Fig. 4. Note that we calculated the stresses at $x=0, x=0.2 \mathrm{~m}$, etc. in accordance with the algorithm described in [14], since in Fig. 4 voltages are given for slightly different values of the x coordinate.

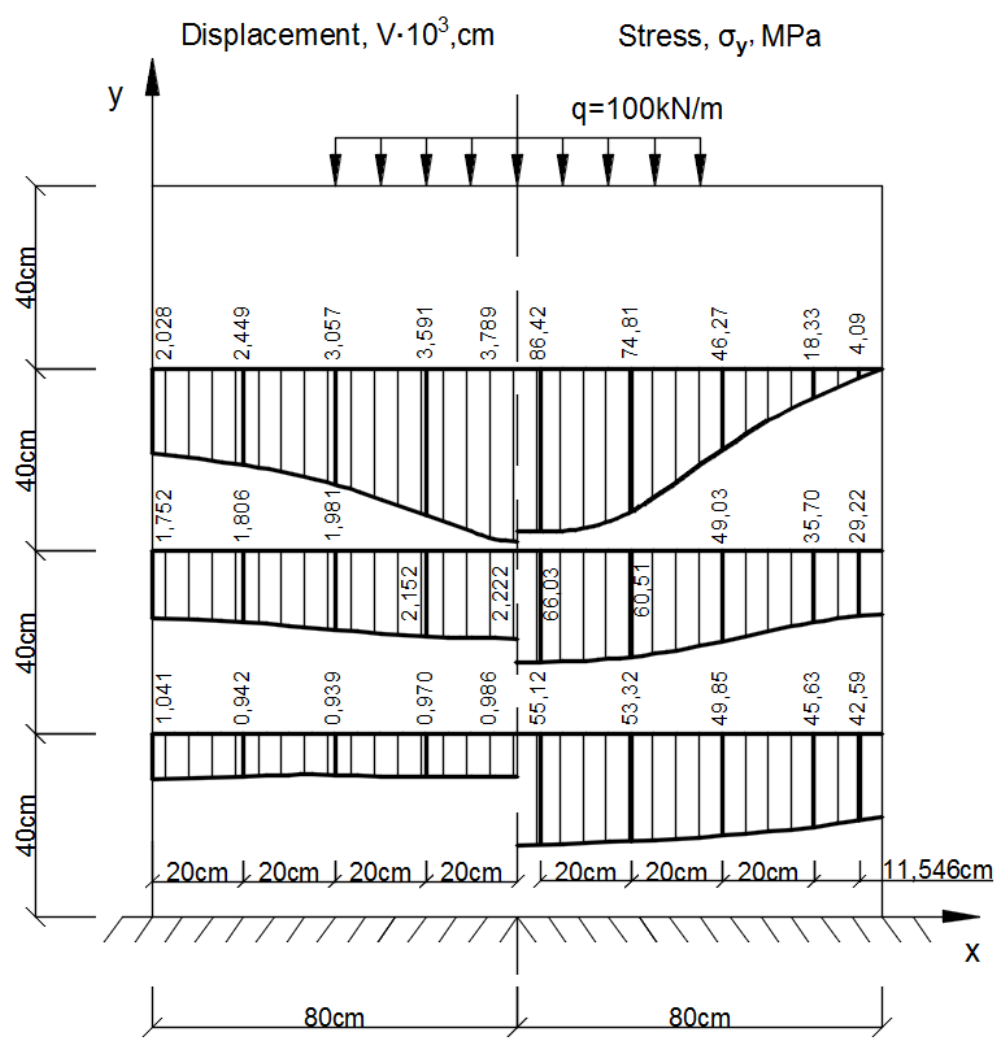

Fig. 4. Stresses and displacements by A.V. Aleksandrov [14].

Comparison of stresses and displacements calculated by the numerical-analytical method of boundary elements, the finite element method and the obtained A.V. Aleksandrov [14], is given in Tables 1 and 2. 
Table 1. Normal stresses comparison $\sigma_{y}$, MPA.

\begin{tabular}{|c|c|c|c|c|c|c|c|c|c|}
\hline & \multicolumn{3}{|c|}{ NA BEM } & \multicolumn{3}{c|}{ FEM } & \multicolumn{3}{c|}{ Aleksandrov solution [14] } \\
\hline $\mathrm{x}$ & $\mathrm{y}=0,4$ & $\mathrm{y}=0,8$ & $\mathrm{y}=1,2$ & $\mathrm{y}=0,4$ & $\mathrm{y}=0,8$ & $\mathrm{y}=1,2$ & $\mathrm{y}=0,4$ & $\mathrm{y}=0,8$ & $\mathrm{y}=1,2$ \\
\hline 0,0 & 1,3701 & $-25,7672$ & $-41,5316$ & 1,7067 & $-26,622$ & $-42,066$ & 1,09 & $-27,22$ & $-41,78$ \\
\hline 0,2 & $-22,5804$ & $-37,5958$ & $-47,5903$ & $-24,298$ & $-38,444$ & $-47,698$ & $-20,33$ & $-37,58$ & $-47,53$ \\
\hline 0,4 & $-52,1359$ & $-51,3737$ & $-50,3471$ & $-53,202$ & $-52,259$ & $-50,375$ & $-50,67$ & $-51,64$ & $-50,34$ \\
\hline 0,6 & $-78,6468$ & $-61,7784$ & $-53,5555$ & $-79,089$ & $-62,700$ & $-53,501$ & $-77,48$ & $-61,77$ & $-53,68$ \\
\hline 0,8 & $-88,4328$ & $-66,2898$ & $-54,5779$ & $-88,529$ & $-66,570$ & $-54,787$ & $-88,32$ & $-66,31$ & $-55,32$ \\
\hline 1,0 & $-78,6468$ & $-61,7784$ & $-53,5555$ & $-79,089$ & $-62,700$ & $-53,501$ & $-77,48$ & $-61,77$ & $-53,68$ \\
\hline 1,2 & $-52,1359$ & $-51,3737$ & $-50,3471$ & $-53,202$ & $-52,259$ & $-50,375$ & $-50,67$ & $-51,64$ & $-50,34$ \\
\hline 1,4 & $-22,5804$ & $-37,5958$ & $-47,5903$ & $-24,298$ & $-38,444$ & $-47,698$ & $-20,33$ & $-37,58$ & $-47,53$ \\
\hline 1,6 & 1,3701 & $-25,7672$ & $-41,5316$ & 1,7067 & $-26,622$ & $-42,066$ & 1,09 & $-27,22$ & $-41,78$ \\
\hline
\end{tabular}

Table 2. Displacement comparison $V \cdot 10^{6}, \mathrm{~m}$.

\begin{tabular}{|c|c|c|c|c|c|c|c|c|c|}
\hline & \multicolumn{3}{|c|}{ NA BEM } & \multicolumn{3}{c|}{ FEM } & \multicolumn{3}{c|}{ Aleksandrov solution [14] } \\
\hline $\mathrm{x}$ & $\mathrm{y}=0,4$ & $\mathrm{y}=0,8$ & $\mathrm{y}=1,2$ & $\mathrm{y}=0,4$ & $\mathrm{y}=0,8$ & $\mathrm{y}=1,2$ & $\mathrm{y}=0,4$ & $\mathrm{y}=0,8$ & $\mathrm{y}=1,2$ \\
\hline 0,0 & $-0,2025$ & $-0,1770$ & $-0,1045$ & $-0,20348$ & $-0,17752$ & $-0,10569$ & $-0,2028$ & $-0,1752$ & $-0,1041$ \\
\hline 0,2 & $-0,2451$ & $-0,1805$ & $-0,0932$ & $-0,24830$ & $-0,18151$ & $-0,09435$ & $-0,2449$ & $-0,1806$ & $-0,0942$ \\
\hline 0,4 & $-0,3035$ & $-0,1985$ & $-0,0925$ & $-0,30690$ & $-0,19773$ & $-0,09290$ & $-0,3057$ & $-0,1981$ & $-0,0939$ \\
\hline 0,6 & $-0,3572$ & $-0,2143$ & $-0,0968$ & $-0,35747$ & $-0,21365$ & $-0,09586$ & $-0,3591$ & $-0,2152$ & $-0,0970$ \\
\hline 0,8 & $-0,3791$ & $-0,2211$ & $-0,0983$ & $-0,37794$ & $-0,22007$ & $-0,09727$ & $-0,3789$ & $-0,2222$ & $-0,0986$ \\
\hline 1,0 & $-0,3572$ & $-0,2143$ & $-0,0968$ & $-0,35747$ & $-0,21365$ & $-0,09586$ & $-0,3591$ & $-0,2152$ & $-0,0970$ \\
\hline 1,2 & $-0,3035$ & $-0,1985$ & $-0,0925$ & $-0,30690$ & $-0,19773$ & $-0,09290$ & $-0,3057$ & $-0,1981$ & $-0,0939$ \\
\hline 1,4 & $-0,2451$ & $-0,1805$ & $-0,0932$ & $-0,24830$ & $-0,18151$ & $-0,09435$ & $-0,2449$ & $-0,1806$ & $-0,0942$ \\
\hline 1,6 & $-0,2025$ & $-0,1770$ & $-0,1045$ & $-0,20348$ & $-0,17752$ & $-0,10569$ & $-0,2028$ & $-0,1752$ & $-0,1041$ \\
\hline
\end{tabular}




\section{Conclusions}

Thus, an approach has been developed to solve the biharmonic equation of the plane problem of the theory of elasticity by the numerical-analytical method of boundary elements. The solution covers all boundary conditions for which systems of fundamental orthonormal functions and the Green function are constructed.

A numerical example of solving a plane problem by the boundary element method for a rectangular plate is considered. The results are compared with the data of finite element analysis in the ANSYS program and those obtained by A.V. Aleksandrov [14].

Tables 1 and 2 analysis shows that the results of the calculation by the boundary element method are in good agreement with the results of calculations in ANSYS and with the data given in [14].

\section{References}

1. Samul, V. I. (1982). Osnovyi teorii uprugosti i plastichnosti: Ucheb. posobie dlya studentov vuzov.(2), pererab.,M.: Vyissh. shkola, 264.

2. Timoshenko, S.P., Guder, D.Zh.. (1975). Teoriya uprugosti. M.: Nauka, 576.

3. Amenzade, Yu.A. (1976). Teoriya uprugosti. M.: Vyisshaya shkola, 272.

4. Demidov, S.P. (1979). Teoriya uprugosti. M.: Vyisshaya shkola, 432.

5. Kayumov, R.A. (2016). Osnovyi teorii uprugosti i elementyi teorii plastin i obolochek: Uchebnoe posobie. Kazan: Izd-vo Kazansk. gos. arhitek.-stroit. un-ta, 111.

6. Aliev, A.V., Kalinnikov, A.E. (2014). Chislennoe reshenie ploskoy zadachi lineynoy teorii uprugosti s netrivialnoy geometriey metodom granichnyih elementov. Vestnik Izhevskogo gosudarstvennogo tehnicheskogo universiteta. 1, 151-154.

7. Ovskiy, A.G. (2014). Modelirovanie ploskih zadach teorii uprugosti tolstyih mnogosloynyih plit v sistemah kompyuternoy matematiki. VIsnik ZaporIzkogo natsIonalnogo unIversitetu 2, 101-116.

8. Zamyatin, V.M., Mahov, A.V., Svetashkov, A.A. (2006). Reshenie ploskih zadach teorii uprugosti dlya polosyi s pomoschyu diagonalizovannoy sistemyi uravneniy ravnovesiya. Izvestiya Tomskogo politehnicheskogo universiteta, 309 (6), 135-139.

9. Tokovyi, Yu. V., Rychahivs'kyi, A. V. (2005). Analytic Solution of the Plane Problem of the Theory of Elasticity for a Nonuniform Strip. Materials Science, 41 (1), 135-138.

10. Li, Lian He; Fan, Tian You (2008). Complex variable function method for the plane elasticity and the dislocation problem of quasicrystals with point group $10 \mathrm{~mm}$. Physics Letters A, 372 (4), 510-514.

11. Elakkad, A., Bennani, M.A., Mekkaoui, J. EL, Elkhalfi, A. (2013). A Mixed Finite Element Method for Elasticity Problem. International Journal of Advanced Computer Science and Applications, 4 (2), 161-166.

12. Daschenko, A.F., Kolomiets, L.V., Orobey, V.F., Surianinov, M.G. (2010) Chislennoanaliticheskiy metod granichnyih elementov. Odessa: VMV, 1, 416, 2, 512.

13. Orobey, V.F., Surianinov, M.G. (2011). Osnovnyie polozheniya chislennoanaliticheskogo varianta MGE. St. Petersburg: St. Petersburg Polytechnic Universities Press, 4 (22), 33-39.

14. Aleksandrov, A.V., Potapov, V.D. (1990). Osnovyi teorii uprugosti i plastichnosti. M.: Vyisshaya shkola, 398. 
15. Vlasov, V.Z. (1962). Izbrannyie trudyi: V 3t. M.: Izd-vo AN SSSR, 1963.

16. Kiyasov, S.N., Shuryigin, V.V. (2011). Differentsialnyie uravneniya. Osnovyi teorii, metodyi resheniya zadach: Uchebnoe posobie. Kazan: Kazanskiy federalnyiy universitet, 112.

17. Mushelishvili, N.I. (1966). Nekotoryie osnovnyie zadachi matematicheskoy teorii uprugosti. M.: Izd-vo AN SSSR, 707.

18. Zaytsev, V.F., Polyanin, A.D. (2003). Spravochnik po differentsialnyim uravneniyam s chastnyimi proizvodnyimi pervogo poryadka. M.: Fizmatlit, 416.

19. Alekseev, E.R., Chesnokova, O.V., Rudchenko, E. A. (2008). Scilab: Reshenie inzhenernyih i matematicheskih zadach. M.: ALT Linux; BINOM. Laboratoriya znaniy, 269.

20. Simona De Cicco, Fabio De Angelis. A plane strain problem in the theory of elastic materials with voids. Mathematics and Mechanics of Solids. 2020; 25(1): 46-59.

21. Tyukalov, Yu.Ya. Equilibrium finite elements for plane problems of the elasticity theory. Magazine of Civil Engineering. 2019. 91(7). Pp. 80-97. DOI: 10.18720/MCE.91.8.

22. Svanadze, M. Steady vibration problems in the theory of elasticity for materials with double voids. Acta Mech 2018; 229(4): 1517-1536.

23. Svanadze, M. Fundamental solutions in the theory of elasticity for triple porosity materials. Meccanica 2016; 51(8): 1825-1837.

24. Svanadze, M. Potential method in the theory of elasticity for triple porosity materials. $\mathbf{J}$ Elasticity 2018; 130(1), DOI: 10.1007/s10659-017-9629-2. 